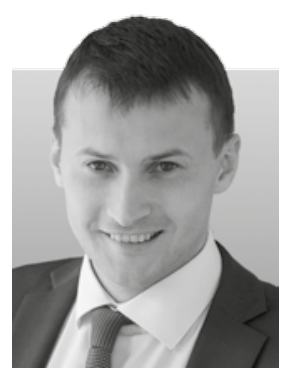

И.А. ДОЛМАТО Кандидат экон. наук, директор Института ироблем ценообразования и регулирования естественных монополи Национального исследовательского школа экономики». Област научных интересов: тарифообразование и инвестиционная деятельность в отраслях естественных монополий и инфраструктуры, процесс либерализации естественн монополий в Ро и за рубежом.

E-mail: idolmatov@hse.ru

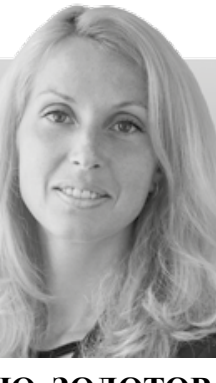

\section{И.Ю. ЗОЛОТОВА}

Заместитель директора Института проблем
ценообразования и регулирования естественных монополий Национального исследовательского университета «Высшая научных интересов: система государственного регулирования естественн монополий, ценообразовани модели прогнозирования цен в электроэнергетик и инфраструктурных

E-mail: izolotova@hse.ru

ПEPEKPECTHOE СУБСИДИРОВАНИЕ В ЭЛЕКТРОЭНЕРГЕТИКЕ. КАКОВ ПРЕДЕЛ РОСТА?

АННОТАЦИЯ

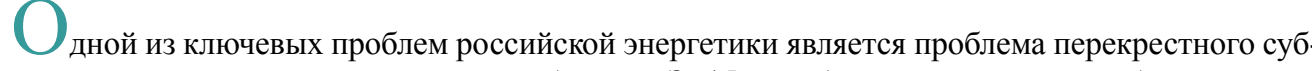
сидирования разными группами потребителей. 3а 15 лет объем перекрестного субсидирования в России вырос в 4 раза. Оценен условно допустимый уровень перекрестного субсидировани исходя из дополительной тарифной нагрузки на промышленых потребителей, связанной субсидирования рекоменлуется ежегодно увеличивать тарифы на электроэнергию для населения на $6 \%$. На переходном этапе к целевой модели следует исходить из предельной тарифной нагрузки на промышленных потребителей; в качестве «эталона» такого предела могут выступать розничные цены на электроэнергию для аналогичных потребителей Европы (возможное увеличение тарифов на электроэнергию для промышленных потребителей в среднем по России составляет 1,4 раза от уровня 2016 года). Предложены варианты сокращения перекрестного субсидирования и рекомендации, как определять соответствующие объемы, что важно в текущих условиях отсутствия единой принятой методологии оценки как самой величинь

В целевой модели ценообразования на электрическую энергию механизм перекрестного суб-

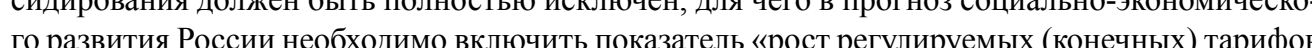
дия населенияу (вернуть сушествовавшую до 2017 года практику), прелусмотрев опережающие темпы роста по сравнению с прочими потребителями.

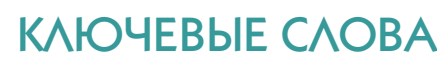

ЭЛЕКТРОЭНЕРГЕТИКА, ПЕРЕКРЕСТНОЕ СУБСИДИРОВАНИЕ, ТАРИФЫ

ЭНЕРГИЮ ДЛЯ ПРОМЫШЛЕННОСТИ, ПРОГНОЗ

\section{АНААИЗ ТЕКУЩИХ}

\section{ТЕНАЕНЦИЙ}

Сегодня средневзвешенные цены на электрическую энергию для прочих выше, чем для населения, что противоречит экономическим приншипам формирования соответствуюших цен [Зототова И. Ю 2017; Линдер Н.В., Трачук А.В., 2017]. Прочие потребители (в основном крупные промышленные предприятия) несут дополнительную тарифную нагрузку, оплачивая часть стоимости электроэнергии, поставляемой населению (механизм перекрестного субсидирования») [Трачук А.В., Л С 2004 года объем перекрестно о

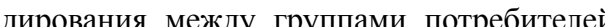

вырос в четыре раза (с 69 млрд рубб. до 283 замедления/сокращения темпов роста величины перекрестного субсидирования и существенного увеличения соответствующих ьемов (рис. 1):

2004-2006 годы - превышение темлор роста цен на электроэнергию для прочих потребителей позволило сократить объемы перекрестного субсидирования (в реальных ценах);

2007-2011 годы - дальнейшее существенное (более чем на 5 п.п.) опережение темпов роста тарифов для прочих потребителей над ростом цен на электроэнергию для населения привело к резкому увеличению объемов перекреспого субсидиро
• 2012-2017 годы - тенденции последних пяти лет (незначительные отличия по темпу роста розничных цен на электроге рекрестного субссидирования.

Pис. 1. Динамика розничных цен на электроэнергию и объемов
перекрестного субсидирования (по данным ОАО «РАО ЕЭС России", ЗАО «АПБЭ", ФСТ России)

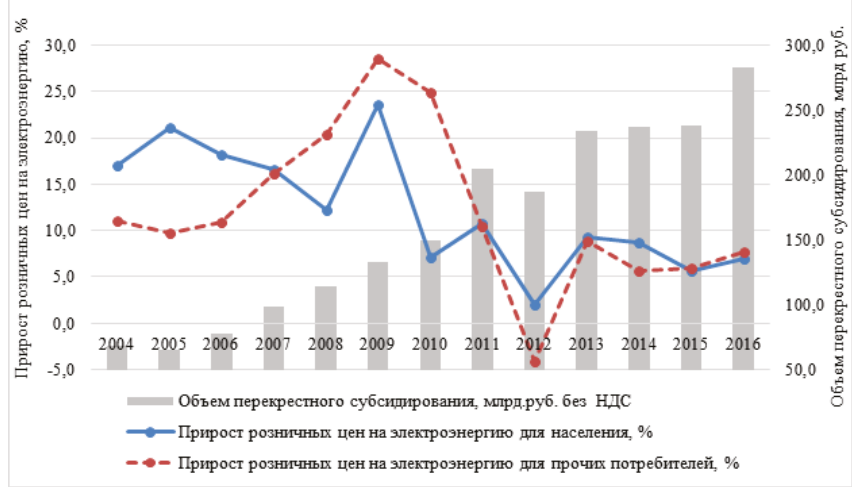

Для сокращения объемов перекрестного субсидирования необходимо, чтобы розничные (конечные!) цены на элекнеобходимо, чтобы розничные (конечные!) цены на элекпо сравнению с ценами для прочих потребителей.

Начиная с 2017 года в прогноз сошиально-экономического развития, который готовит Минэкономразвития России на три года, включены параметры, отражающие перспективный рост электросетевых тарифов для населения и для прочих потребителей, индексы изменения платы граждан за коммунальные услуги. Из прогноза исключены показатели прогнозных пзменений конечных цен на электроэнергию для населения.

Прогнозом предусмотрен опережающий с 2017 года темп росла (па 2..п.) сетевых тарифов на электроэнергию для насебителей. Таким образом, задан целевой вектор, направтенный на ликвидашию (сограшение) перекрестного субсиривровый [Прогноз социально-экономического развития].

С учетом особенностей ценообразования для населения ${ }^{1}$ [Прогноз, [б.г.]] обозначенные параметры прогноза не могут быть достигнуты. Дополнительным препятствием оказывается ограничение по темпам роста платы граждан за коммунальные услуги (не выше 4\%), когорое является индикатором для предельной индексации конечного тарифа

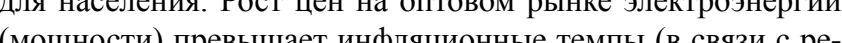
ализашией договоров о представтении монности), а значит, прирост сетевого тарифа для населения по факту может быть ниже не только обозначенних в прогнозе параметров, но и ниже 4\% как ориентира. За 2016 год при одинаковых параметрах прироста сетевого тарифа для населения и прочих потребителей (в соответствии с прогнозом - 7,5\%) темпы роста розничных цен на электроэнергию для прочих потре- бителей сложились вьше селения [Ассоциация, [б.г.]].

Для того чтобы обеспечить прозрачность в решении задач по сокращению перекрестного субсидирования (с учеэнергию для населения), необходимо включить в прогноз показатель «рост регулируемых (конечных) тарифов для населения» (как было до 2017 года), предусмотрев опережающие темпы роста по сравнению с прочими потребителями [Долматов И. А., Золотова И. Ю., Маскаев И. В., 2017].

Номимо дифференциации темпов изменения тарифов для рассматриваемых групп потребителей на динамику объемов перекрестного субсидирования также влияет различие групп потребителей. По огенкам Минэнерго России и ряда ген

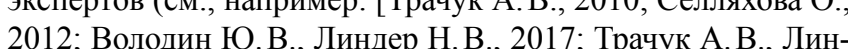
дер Н. В. 2017]), тенденшии послепних пет, характеризуюшиеся превьшением темпов роста электропотребления населением по сравнению с прочими потребителями (рис. 2), сохранятся на ближайшие годы, что при прочих равных условиях приведет к росту объемов перекрестного субсидирования в перспективе (на рис. 3 показана неизменность тарифов на электроэнергию для населения, ежегодный прирос эжекропотребления $-1,5 \%$ ).

Рис. 2. Динамика электропотребления, прирост кпредыдущему году [Ассоциация, [б.г..]]

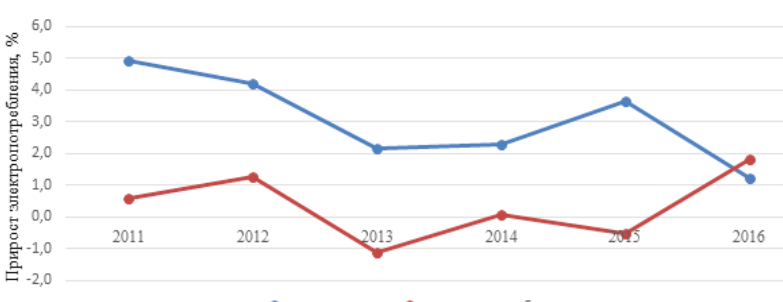

Рис. 3. Объем перекрестного субсидирования (прогноз без НДС), млрд руб.

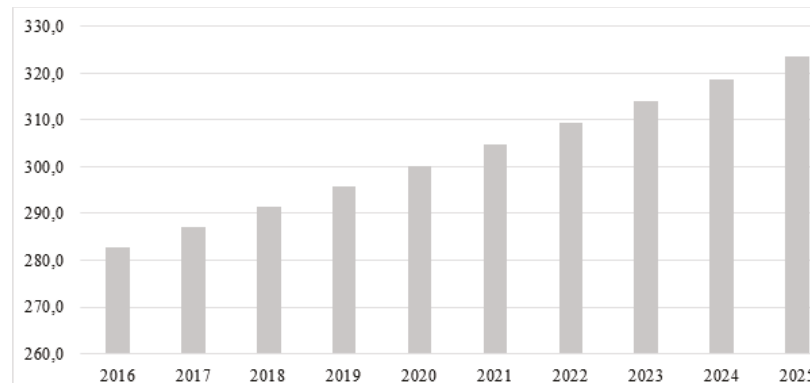


Рис. 4. Уровень цен на электрическую энергию для бытовых и промышленных потребителей в Российской Федерации и в странах Европы (без учета налогов) в 2015 году, евроцент/кВт·ч [Eurostat, [б.г.]]

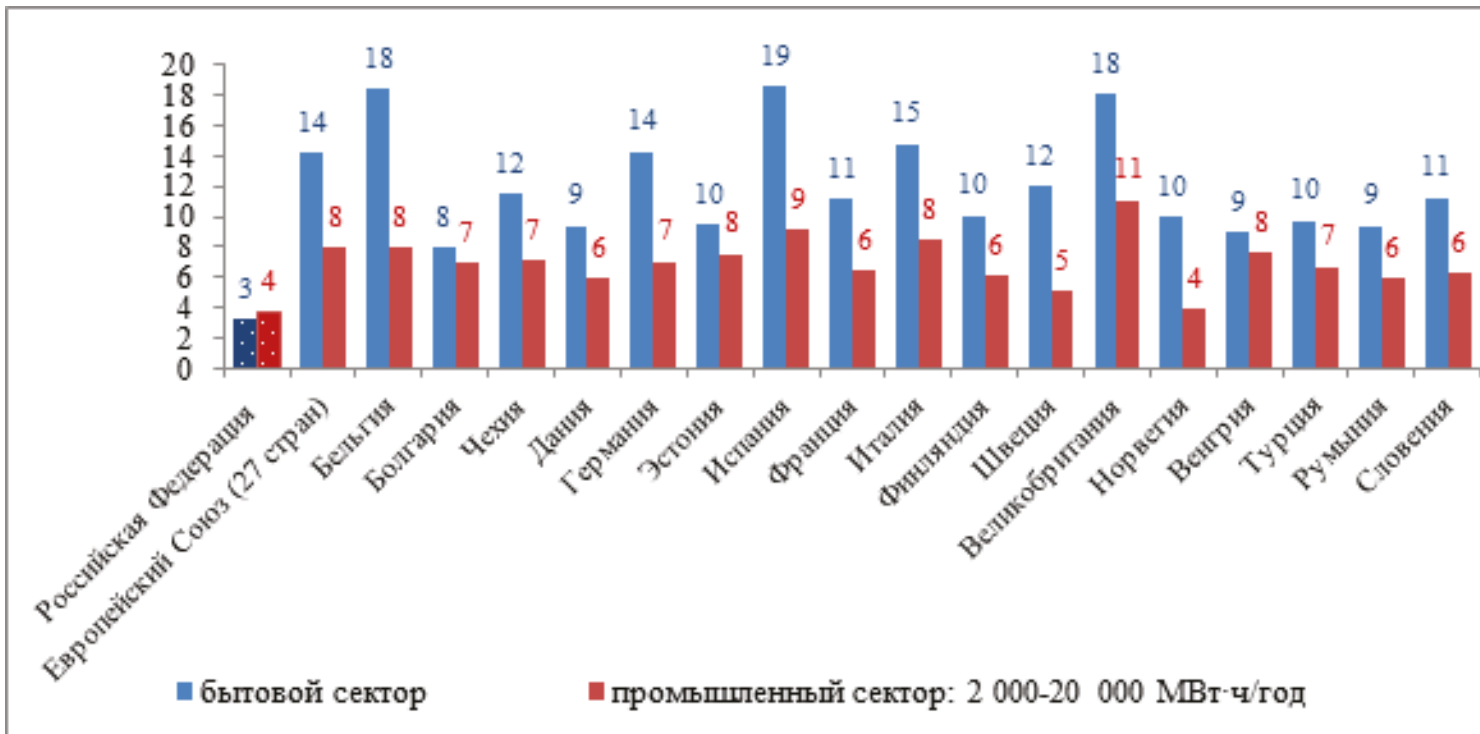

ОЦЕНКА АОПУСТИМОГО УРОВНЯ ПЕРЕКРЕСТНОГО СУБСИАИРОВАНИЯ

Рассматривая проблему перекрестного субсидирования, необходимо учитывать текущий уровень розничных цен на электроэнергию для промышленных предприятий (которые сегодня несуг нагрузку нй ных потребитепей (особенно для крупных энергоемких потребителей, для которых цена на электроэнергию является существенным фактором, влияющим на конкурентоспособность продукции). В качестве эталона такого предела могут выступать розничные цены на электроэнергию для аналогичных потребителей в Европе (рис. 4).

Как показал анализ цен на электроэнергию для промышленного сектора в странах со схожей структурой бытового и промышленного потребления электроэнергии (Бельгия, Германия, Финлядия, Румыния), есьь возможность сти в сре нем по России не боле чем в 1,4 pas от уровня 2016 года, или до 4,2 руб./кВт·ч (при этом потенииал роста тарифов для населения сушественный; фактический тариф на электроэнергию для населения в 2016 году составил 2,4 руб./кВТ·ч без НДС, для прочих потребителей $-3,1$ pyб./кBТ·ч) [Eurostat, [б.г.]].

Итак, текущий уровень перекрестного субсидирования в целом по России условно допустим с точки зрения тарифной нагрузки на промышленных потребителей. В ряде субъектов Российской Федерации действующие тарифы на электроэнергию для промышиленых норебителей близки мер, Республика Алтай, Костромская область, Архангетскея, Респубблика Алтай, Костромская область, Архангельпотребителей (в том числе в связи с нагрузкой по перекрестному субсидированию) может привести к тому, что крупные потребители перейдут на альтернативные источники элек-

ПЕРЕКРЕСТНОЕ СУБСИАИРОВАНИЕ: MЕТОАОАОГИЯ ОПРЕАЕАЕНИЯ зования мощности для различных тарифных групп). пу минимизации совог
[Долматов И., Золотова И., 2015]. Таким образом, невозосновании при ценообразовании регулятор не делает разлииндивидуализация тарифного меню розничных потре-

Расчет величины перекрестного субсидирования существенно зависит от того, как определять экономически обо

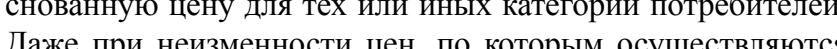
фактические расчеты за эектроэнергию и сопутствуюшис услуги, изменение законодательства, регламентирующего порядок расчета экономически обоснованной цены, моге привести к увеличению или сокращению перекрестного субсидирования (например, при изменении количества уровней напряжения или порядка формирования числа часов исполь-

Объективно невозможно однозначно и достоверно определить издержки отрасли, связанные с поставкой электро энергии каждому конкре,ному погребителю (за исключением случаев автономного энергоснабжения). В общей энерв энергообеспечении всей совонупности потребитегей одновременно. Сама энергосистема спроектирована по принши(причем не только электрической, но и тепловой энергии)

отсутствие существенного давления темпов роста та-

рифов для населения на уровень инфляции);

компенсация совокупных необходимых обоснованных издержек отрасли (рост выручки суммарно по всем можно определить состав оборудования (и, как следствие, издержек), обоснованный с позиции энергоснабжения кон-

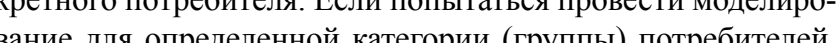
неизбежно возникеет пробтема обосновзния той или иной классификации потребителей (например, каковы об̆тективнье отличия в объеме инфраструктуры, необходимой для снабжения домохозяйства и малого магазина? На каком чий для домохозяйств, расположенных на большом расстоянии друг от друга и на разном расстоянии от генерирующего объекта в рамках одного субъекта Российской Федерации?

В силу описанных выше особенностей расчета существуют различные оценки объемов перекрестного субсидиров-

оказывается, зависит от совершенствования метованоя, ческой базы. Цифровизашия процессов управления и оптимизация работы на рынках электроэнергии (мощности) открывают возможности для детализации ценообразования и учета специфических условий поставки электроэнергии (резервирование мощности, учет категории надежности, бителей) [Трачук А.В., Линдер Н.В., 2018; Дзюба А.П., Соловьева И.А., 2018]. Указанное обстоятельство может перекрестного суб̆сидирования и на его величину. Таним образом, предстоит актуализировать соответствуюшие оценки величины перекрестного субсидирования с учетом различных инишиатив по внесению изменений в метолотогию расчета тарифов,

ПРЕАЛОЖЕНИЯ ПО СОКРАЩЕНИЮ ПЕРЕКРЕСТНОГО СУБСИАИРОВАНИЯ

ежегодный прирост цен (тарифов) на электроэнергию для населения $-6 \%$, для прочих потребителей $-3 \%$ (сщенарий индексации «инфляция минус»),

в ежегодная индексация расчетного экономически обосноВклад прироста тарифов на эгектроэнергию для населевия в размере $6 \%$ в индекс потребительских цен состави 0,075 п.П. то есть не окажет существенного инфляшионного давления.

Рис. 5. Прогноз сокращения перекрестного субсидирования 2,0 20162017201820192202020212022202320242025202620272028 -

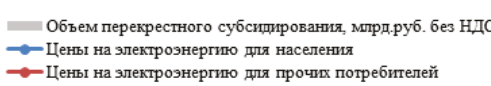

При заданных сценариях расчетов до 2025 года уровни цен на электроэнергию для населения и прочих потребителей будуг сблжаться, начина с 2025 года тарифы для наседля прочих потребителей; к 2028 году об̆ъем перекрестного суб̆сидирования сократится до 234 млрд руб. (на 49 млр руб. за 10 лет)

В целевой модели ценообразования на электрическую энергию механизм перекрестного субсидирования должен быть полностью исключен (объем перекрестного субсидирования сведен к нулю): средний уровень тарифов на электрическую энергию для населения должен покрывать реальные издержки по производсву, передаче и распределению энергии данной группе потребителей. Для поддержки малоиму щих граждан неббходио испольовать механизм адресно юшего законодатепстра инструмент подтержки по оплате коммунальных услуг.

При определении прогнозной динамики сокращения пеекрестного субсилирования необходимо, чтоби менно выполнялись следуюшие условия:

- опережаюшие темпы роста тарифов для населения;

рост цен для прочих потребителей в целом за прогнозный период не более чем в 1,4 раза (с учетом действующего курса «евро/рубль»), или до 4,2 руб./кВт·ч от уровня 2016 года (c дальнейшем существенным замедлением темпов роста), чению соответствующих затрат).

На рис. 5 представлен прогноз розничных цен на этекроэнергию для населения, прочих потребителей и оббемов перекрестного субсидирования, сформированный с учетом следующих сценариев:

ежегодный прирост электропогребления населением -

$1,5 \%$, прочими потребителями $-0,5 \%$;
Как показывают модельные расчеты, при рассматрива-

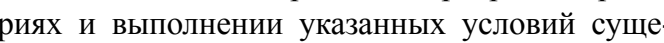
ственного сокращения объемов перекрестного субсидироваиия можно достичь к 2036 году (рис. 6 ).

Рис. 6. Объем перекрестного субсидирования (1)

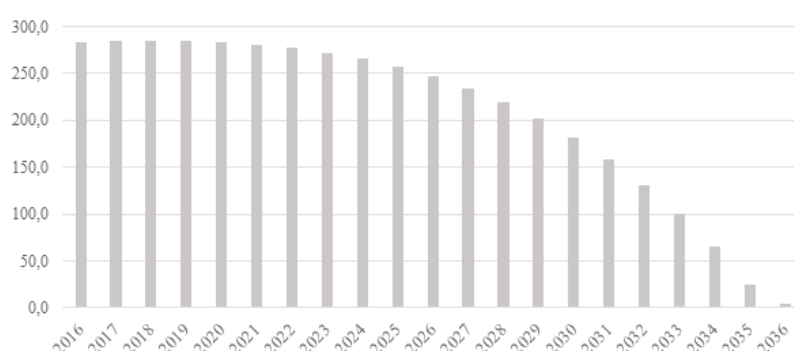


В соответствии с нормативными правовыми актами к 2022 году предусмотрено поэтапное снижение объемов перекрестного субсидирования до оптимального уровня, зяйств (в ценах 2012 года составлеет оголо 45-50 млрп руб. примерно для 30\% домохозяйств) [Распоржение 2013]. В рассматриваемых сценариях данный уровень может быть достигнут не ранее 2032 года. Для выполнения указанных целевых параметров необходимо, чтобы ежегодно тарифы на электроэнергию для населения росли интенсивнее (прирост не менее $10 \%$ в год).

\section{ВЫВOАЫ}

1. В целевой модели ценообразования на электрическую энергию механй перекрестного субсидирования должен быть полностью исключен,

2. Необходимо вернуть существовавшую до 2017 года практику - включить в прогноз социально-экономического развития России показатель крост регулируемых (конечных) тарифов для населения», предусмотрев опережающие тем

3. Рекомендуемьй ежегодньй прирост тарифов на элекроэнергию для населения в целях сокрашения перекрестного субсидирования составляет 6\%. При определении допустимого уровня перекрестного субсидирования (на переходном этапе к целевой модели) следует исходить из предельной тарифной нагрузки на промышленных потребителей; в качестве эталона допустимо принять розничные цены на электроэнергию для аналогичных потребителей в Европе (для промышленных потребителей в среднем по России возможное увеличение тарифов на электроэнергию составляет 1,4 раза от уровня 2016 года).

стного субсидирования можно корру различные инишиативы по внесению изменений в метолотогию расчета тарифов, следует актуализировать соответствующие оценки величины перекрестного субсидирования.

\section{АИТЕРАТУРA}

. Ассоциация НП «Совет рынка» ( [б.г.]). URL http://www.np-sr.ru.

2. Володин Ю. В., Линдер Н. В. (2017) Тарифная политика и перекрестное субсидирование в электро- и теплоэнергетике // Стратегии бизнеса. № 1. С. 37-47.

3. Дзюба А.П., Соловьева И.А. (2018). Управление спросом на электропотребление в России // Стратегические

perar C. 32-35.

5. Долматов И.А., Золотова И. Ю., Маскаев И. В. (2017) Новый тарифный режим для естественных монополий в России: каким он должен быть? // Эффективное Антикризисное Управление. № 3-4. С. 30-37.
6. Золотова И. Ю. (2017). Перекрестное субсидирование в электроэнергетике: эмпирический анализ, оценка Антки (2017). B ного субсидирования в электро- и теплоэнергетике на изменение поведения участников оптового и розничного рынков электро- и теплоэнергии // Эффективное Антикризисное Управление. № 3 (101). С. 78-86.

8. Постановление Правительства РФ от 29.12.2011 № 1178 (ред. от 17.02.2018) «О ценообразовании в области регулируемых цен (тарифов) в электроэнергетике» // КонсультантПлюс. URL: http://www.consultant.ru/document/cons_doc_

LAW_125116

9. рио 2019 и 2020 годов ( [о г]) // но псультанППеURL. http://www consultant ru/document/cons_doc LAW_282738/.

10. Распоряжение Правительства РФ от 03.04.2013 № 511-p (ред. от 29.11.2017) «Об утверждении Стратегии развития электросетевого комплекса Российской Федерации» // КонсультантПлюс. URL: http://www.consultant.ru/document/cons_doc

11. Ряпин И. (2013) Перекрестное субсидирование в элекгетнергетике: итог пятнадцатилетней борьбы/Энср«Сколково». М. $97 \mathrm{c}$.

12. Селляхова О. (2012) Перекрестное суббсидирование и социальная норма электропотребления // Эффектиеное Антикризисное Управление. № 6. С. 32-48.

3. Трачук А. В. (2011a). Развитие механизмов регулирования электроэнергетики в условиях ее реформирования // Экономика и управление. № 2 (64). С. 60-63.

4. Трачук А.В. (2010). Риски роста концентрации на рынке электроэнергии/Энергорынок. № 3. С. 28-32.

15. Трачук А.В. (2011б) Реформирование естественных M: Эron.

16. Трачук А. В. Л

Лрачук А.В., Линдер Н. В. (2017) Перекрестное суб̆сииирование в электроэнергетике: подходы к моделированию снижения его объемов // Эффективное Антикризисное Управление. № 1 (100). С. 24-35.

7. Трачук А. В., Линдер Н. В. (2018). Технологии распределенной генерации: эмпирические оценки факторов ирименения // Стратегические решения и риск-мене-

жмент. № 1. С. 32-50.
18. Трачук А. В., Линдер Н. В., Зубакин В.А. и др. (2017) Лерекрестное субсидирование в электроэнергетике: $121 \mathrm{c.}$

. Ховалова Т. В. (2017). Моделирование эффективности Антикризисное Управление. № 3 (102). С. 44-57.

20. Eurostat. URL: http://ec.europa.eu/eurostat/web/main/ home.

\section{подписаться на журнал}

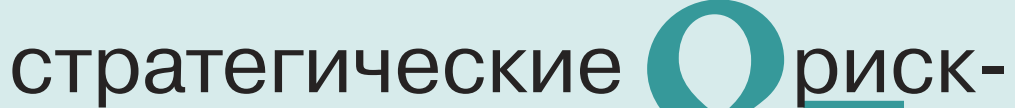 решения менеджмент}

Подписка через редакцию

\section{СТОИМОСТЬ ПОДПИСКИ:}

на 6 месяцев - 1180 рублей (2 номера)

на 12 месяцев - 2360 рублей (4 номера)

В стоимость включены почтовая доставка и НДС

на PDF-версию на год (с НДС) - 1416 руб. (журнал будет приходить на ваш mail) Всем студентам и преподавателям скидка $50 \%$ при подписке на печатную или PDF-версию журнала

Подписка через агентства:

• Агентство «Роспечать», каталог «Газеты. Журналы» - подписной индекс 33222

Интернет-магазин подписки на периодику Presscafe

- Агентство «АРЗИ», каталог «Пресса России» - подписной индекс 88671

Подписка на журналы и газеты через интернет-каталог

• Агентство «МАП», каталог «Почта России» - подписной индекс 3585

Онлайн-версия: каталог российской прессы «Почта России»

- Агентство ООО «Урал-Пресс» во всех регионах РФ

Подписка на электронную версию через сайт Delpress.ru, ЛитPеc, Пресcа.py

- Агентство ЗАО «ПРЕССИНФОРМ», г. Санкт-Петербург

\section{ДОПОЛНИТЕЛЬНАЯ} ИНФОРМАЦИЯ:

ТЕЛ. + 7 (812) 346-50-15 (-16)

ФАКС: + 7 (812) 325-20-99

E-MAIL: podpiska@jsdrm.ru WWW. jsdrm.ru

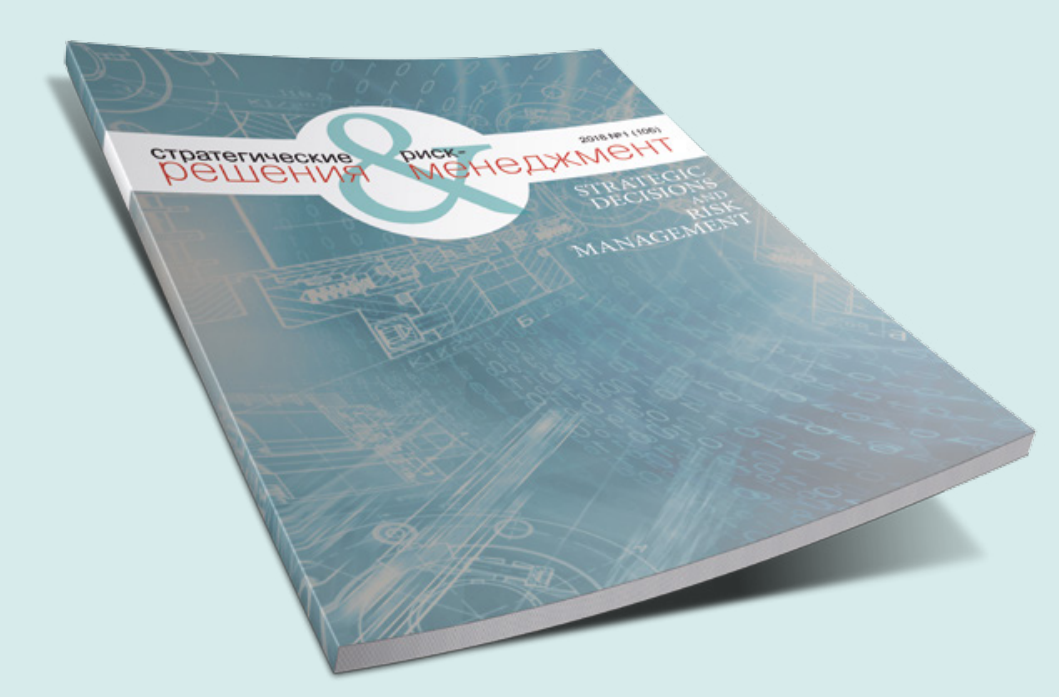

